\title{
Social Sustainability in Design: The Window as an Interface for Social Interaction
}

\author{
Gaia Scagnetti and Federico Casalegno \\ Mobile Experience Lab, 20 Ames Street, E15-320, Cambridge, MA 02139, USA \\ gaia.scagnetti@gmail.com, casalegno@mit.edu
}

\begin{abstract}
The way people organize the space of their house is strongly related to their local culture. In the process of designing a sustainable home not only is fundamental to make architectural choices toward an environmental and economical sustainability but it is also imperative to pay attention to the process of integration in the local cultural environment. This paper presents the results of an ethnographic research that informs and understands the implementation of a Sustainable Connected Home prototype. The paper demonstrates how the local context and the social sustainability discourse could provide impetus to technological innovation for sustainable design. It also provides a framework for future discussions on the definition of social sustainability in the context of design interventions.
\end{abstract}

Keywords: Architectural design, design research, innovation, case study/studies, social sustainability, qualitative research.

\section{Introduction}

Design plays a fundamental role in addressing the sustainable development, especially when it comes to the house. In the process of designing a sustainable home not only is fundamental to make architectural choices toward environmental and economical sustainability but it is imperative also to pay attention to the process of integration in the local cultural environment: this means equally to use local resources, to respect and learn from the native traditions and benefit from local expertise and to treasure the everyday practices that embody the local culture. In Csikszentmihalyi words: 'Thus the importance of the home depends not only on survival needs (to bring up infants, to sleep and eat in comfort), on the particular economy (hunting pastoral, farming or industrial), or on the climate; it also depends on value, tradition, and literary and religious associations that cannot be predicted from determining conditions' (Csikszentmihalyi and Halton 1981).

As the Design Agenda for Sustainability has stated, it is necessary to 'sustain promising social and technological innovations and to re-orient existing drivers of change towards sustainability' (Manzini 2009); this means to combine the technological development toward a more sustainable society with a reflective research on the social dimension of sustainability; even though the research on environmental sustainability has been carried on for more than 20 years, the social dimension of sustainability has 
been acknowledged only recently and still needs to be questioned and discuss in order to support and foster the development toward a sustainable society.

This paper presents the results of an ethnographic research conducted in Trentino (Italy) in summer 2008 with the purpose of mapping the cultural context where a Sustainable Connected Home ${ }^{1}$ prototype would be implemented in 2010. In our initial hypothesis, the Sustainable Connected Home is a home that is not only built with sustainable materials and that uses green energy, but also takes full advantage of all the digital world has to offer to create a building that can respond to its environment and to the needs of its inhabitants more intelligently. It employs the latest in what we know about artificial intelligence, as well as advanced robotics, to improve the quality of life for those who live in the home. And, going even further, it is a home that by its very existence and the way it works optimizes human behavior and thus promotes social sustainability' (Mitchell and Casalegno 2008). The Sustainable Connected Home has four main design objectives:

- Sustainable architecture; implementation of a vivid and specialized architecture that embodies particular sustainable principles, integrated into the landscape in an efficient and elegant way.

- Smart energy system; use of natural sources of energy for the energy supply of the home such as solar panels, rainwater retention, biomass and windmills.

- Information and communication technologies; integration of information and communication technologies to create a responsive system between users, architecture and energy systems.

- Social sustainability; integration of the individual home with the community with a focus on the social aspects of sustainable living and the local economy

Even though there is almost a consensus about the meaning of environmental and economic sustainability on the contrary the definition, indicators and strategies to address social sustainability remain still under discussion. In particular the discourse on sustainability in the context of design is particularly crucial and opens valuable possibilities for in-depth inquiry.

This paper elaborates on the definition of social sustainability, by presenting a qualitative research results aimed to inform a design project that present technological solution for sustainable design and it attempts to provide a framework for future discussions of the social sustainability definition in the context of design interventions.

\section{Social Sustainability}

Social sustainability has been defined as the third pillar of the tree bottom line of sustainability together with Economic and Environmental spheres (Elkington 1998;

\footnotetext{
${ }^{1}$ A project made within the Green Homes Alliance, between the Mobile Experience Lab, Design Laboratory, at the Massachusetts Institute of Technology, and the Fondazione Bruno Kessler, Italy. The concrete aim of the alliance is the advance research in sustainable architecture and renewable energy. Within the Alliance, we aim to build in 2010 a full scale prototype of a Connected Sustainable Home.
} 
Barron and Gauntlett 2002). 'Social sustainability occurs when the formal and informal processes, systems, structures and relationships actively support the capacity of current and future generations to create healthy and livable communities. Socially sustainable communities are equitable, diverse, connected and democratic and provide a good quality of life' (McKenzie 2004).

Even if the concept is gaining more and more attention since the Bruntland Report (Future 1987) and it has been recognized as a fundamental task for sustainable development, there is still no consensus about its definition and measurements (Colantonio and Lane 2007; Lilley 2009; Littig and Griessler 2005; G.V.R.D. 2004).

Social sustainability has been described in terms of meeting basic needs, overcoming disadvantage, fostering personal responsibility, and social responsibility, foster trusting, harmonious and co-operative behavior, acknowledge cultural and community diversity, and foster tolerance, empowering people to participate in decision-making (Baines and Morgan 2004; Sinner et al. 2004). 'Failure to describe these systems in a holistic manner through the synthesis of their different non-reducible and perfectly legitimate perspectives amounts to reductionism. An implication of the above is the fact that not a single sustainability metric at the moment can claim to comprehensively assess sustainability.' (Gasparatos, El-Haram, and Horner 2007). Some authors has notice a shift from a more qualitative perspective that investigate more soft social factors: 'The development and integration process of indicators is hindered further by the shift in the social sustainability discourse from the in-depth analysis of hard themes towards the inclusion of soft themes, as reviewed earlier. As a result, new sustainability indicators are increasingly focused on measuring these emerging themes rather than improving the measurement of more traditional concepts such as equity and fairness. (..) The chronological analysis of social sustainability themes also shows how traditional themes, such as equity, poverty reduction and livelihood, are increasingly been complemented or replaced by more intangible and less measurable concepts such as identity, sense of place and the benefits of social networks'(Colantonio 2009).

The social sustainability has been very often investigated in relation to the urban context and its community aspects. Bramley et al (2006) i.e. focus on the relationship between urban form and social sustainability and propose two main dimensions to the concept, relating to equity of access and the sustainability or quality of community: 'there is a more collective 'sustainability of community' dimension which, although seemingly more nebulous, is also fundamental to the concept. This second dimension is essentially concerned with the continued viability, health and functioning of 'society' itself as a collective entity, generally under the heading of 'community'. They discuss the fact that strategic planning for urban development has paid much attention to provide accessible jobs and affordable housing but other complementary aspects of equity also deserve attention: community participation, community stability and what they call the sense of place. 


\section{$3 \quad$ Methodology}

This idea of sense of place is here considered of primary importance; protecting and supporting as well as learning and giving value to people sense of place is a key approach for the results of this research; the Sustainable Connected Home case study takes into account the sense of place and discusses its significance in the design process. When designing a sustainable home, considering sustainability from multiple perspectives becomes an essential approach for the success of the project. Of course using sustainable architecture is a fundamental part of the design process; in the Sustainable Connected Home the house will be built using sustainable materials and green energy technologies in order to meet the constructive requirements for a green home.

The objective of this research has been to understand how the design of a house could also foster the social aspect of sustainability. For this purpose, qualitative research has been conducted in the area where the sustainable connected home will be built in order to inform the design process.

The method adopted was basically ethnographic: Firstly, a series of interview were conducted in collaboration with a team of ethnographers from the Sorbonne University, CeaQ ${ }^{2}$ in Zambana (Italy) from the 8th to the 12th of June 2009; 31 people have been interviewed, 17 woman and 14 men, of the age between 19 and 70 of which 10 in a municipal room and 21 in their house and outside or in the principle bar of the village, a meeting place situated in the town center near the most important buildings of the place (the school, the church, the town hall). For this first phase a qualitative research method with an open and semi structured questionnaire has been used.

Secondly, more in depth interviews were conducted in July 2009 directly in the respondents' houses, were the behaviors that were part of their everyday lives could be discussed in order to elaborate the relation between energy, garbage, water saving and consumption.

This analysis presents and interprets the tendencies appeared during the ethnographical research, considering the condition of the observed context and the theoretical board examined to study the phenomenon. The work has been conducted in accordance to the methods of the participant observation and the visual sociology, integrating the use of the photographic tool. The interviews aimed to map the relation among people and houses, the use of space, with a specific focus on three themes:

- the perception of the sustainability and ecology issues,

- the relation with the house,

- the use of space;

The results here presented question the qualitative research findings from a design point of view trying to:

\footnotetext{
2 (Centre d'Etude sur l'Actuel et le Quotidien) directed by Michel Maffesoli at Université Paris Descartes Sorbonne.
} 
- understand how to support and inform the design of a house and in this specific case study the development of the prototype of the Sustainable Connected Home

- investigate the meaning of sustainability when related to the social realm

\section{$4 \quad$ Results}

\subsection{The Social Meaning of the House in Trentino}

The population in Trentino has a widespread attention in behaving in a more sustainable way. Techniques for energy saving as solar panels, thermal coat, double glazing are common. An extensive technical knowledge of these appliances and a diffuse accuracy in conducting everyday practices for saving energy and recycling waste are common. In general people have very technical competences about building materials, energy self-production and management.

Sustainability has not been described as an issue related to large-scale problems as the global warming or the end of natural resources, but in fact has been told as the goal of the everyday life made of small gestures of reverence and respect for the surrounding territory. Sustainability is understood within the everyday life activities, so despite the over-all goal to prevent global warming seems remote and far away, it emerge that design can meet the need of supporting more sustainable everyday behaviors. Those behaviors highlight the importance of designing a house that can support everyday life; the idea of having a home as personal trainer involves building a structure that educates its inhabitants and the broader community so as to encourage behavior consistent with sustainability; this notion finds it confirmation in the conducted research.

The ethnography demonstrated as the house plays a major role in the ecology and sustainability discourse: it works as a link between the person and the territory. As a result it seems that a sustainable house should work not only as a passive connection between inhabitants and local reality but it should become an active translator for opening new possibilities of connection to the local community.

According to respondents' answers, the house is the symbol of belonging to their territory; the connection area between the inside and the outside are very important.

Large windows and a balcony are the elements of the house where the relation with the outside is outlined. Respondents report a wish to eliminate barriers within the house the ideal is to have a single house on one level with a door facing the garden where to eat in direct contact with the outside.

The different spaces inside are desired to be full of light: the idea of open space to catch the light from the outside with big large windows and a living room to share with an access outside on the garden is common to the respondents answers.

In the Sustainable Connected Home design we investigate on the relation among the space outside and inside in order to respect and reinforce the local use of space. The notion of engawa, the Japanese veranda that links the inside of the building with the outside of the building has been used to foster the social behaviors that allow people to communicate and interact with the community. It is a space belonging to the house but at the same time linked to the outside space that represents the interface 
between public and private. It fosters the social behaviors that are typical of Italian culture where people chat from window to window or sit on the porch watching outside. The window in particular resulted of primary importance both in the ethnography results and consequently in our design. We investigated how to combine local culture and social values with innovative technologies and sustainable architecture.

\section{$5 \quad$ Windows as Interfaces}

The window in a house is the element that relates the inside space with the outside space. It encompasses three design functions related to light, view and spatial articulation. As the contemporary building techniques have given relative autonomy to the building form, these three functions could be made by different elements of the house. That means the window has acquired more freedom in shape and in function; 'whilst in classical architecture the window could be considered a beautiful object in itself (which also justified separate analysis of this single element) the beautiful modern window can only be understood in relation to the whole special layout. It has ceased to be an object itself' (Meiss 1990). Taken into account the prior findings of the ethnographic research, the design of the Sustainable Connected Home prototype - that will be build in Trentino (Italy) in summer 2010 - has been designed as an innovative and experimental platform for the discussion about a new role for the window. 'The history of architecture could be written in terms of an ideological and technical struggle between the membrane and the frame, with differing cultures weighing in differently on the balance between solidly opaque and flexibly open, based partly on materials available, but more fundamentally on how definitively inside was to be separated from outside' (Lyndon and Moore 1996).

In the sustainable connected home design the south facade of the house is covered by a dynamic curtain wall with wooden frame and operable triple glazed windows incorporating Electro-chromic and PDLC film. This multifaceted curtain wall allows dynamic management and control of visibility, sunlight penetration and crossventilation. The variable configuration of the curtain wall makes possible the dynamic configuration of clear, opaque, open, and closed elements and establishes the currently optimum or the desirable performance.

The state of the Electrochromic glazing and PDLC film of the curtain wall is controlled by a control system that receives input from an implanted network of sensors, as well as from the inhabitants. We call this design Dynamic Window because it allows dynamic management and control of visibility, sunlight penetration and cross ventilation.

With regard to our ethnographic studies on the use of space and windows in the Trentino area, unconventional fenestration practices that are ecologically, socially and culturally sustainable are being explored in this architecture project.

From an architectural point of view the building is designed to perform sustainability under all combinations of environmental conditions. It can dynamically reconfigure its state by taking into account both real-time conditions and long-term goals to optimize its performance. Furthermore, the use of electronically activated variable 
transmission materials for the design of an interactive, programmable building façade that can exercise environmentally and socially sustainable building behaviors has been explored.

Different applications for this façade have been investigated: automated climate moderation, lighting, view and privacy controllers have been designed in order to foster the aesthetic, social, and cultural implications of the use of the house windows. 'The opening and closing of the windows blinds during different times of the day are important social rituals in different cultures. Windows welcome the new morning, signify the waking up of the inhabitants and communicate their availability to the neighbors. For the dynamic façade, the response to the morning and evening sun can also be exercised by subtle gestures' (Telhan et al. 2010). The importance that windows and balconies have in Trentino culture create a fertile context to experiment the Dynamic Windows technologies both as a platform for testing innovative technologies and as a dimension of research on social sustainable design.

'At stake in every understanding of the window is an interpretation of architecture and of politics, an implicit setting and definition of the terms in which they will be elaborated, practiced, and contested' (Keenan 1993).

The façade is not only the climate moderator, but also the screen that mediates the social dynamics between the inside and outside of the built environment. (..) Thus, conceiving new roles for the building façade is an interesting interaction design challenge when the façade can actively be configured for new relationships between the inside and outside; the environment and the house, the house and its inhabitants as well as the inhabitants among themselves and with their neighbors (Telhan et al. 2010). In (Csikszentmihalyi and Halton 1981) words: 'the house [is seen] primarily as a place where people interact with each other; when the home is seen in positive terms, it is because the interaction is harmonious'. For this reason the Connected Sustainable Home façade allows the user to define its view area designing the window frame cell. Without prescribing a fixed frame as the 'window,' the entire façade can be configured as a series of openings that can admit light and allow the inhabitants themselves to determine how much they would like to reveal themselves to the outside world. Electrically activated chromic can also be configured to dynamically respond to passer-by and allow the façade to follow the presence of a user by a series of embedded sensors. Over the completely transparent façade, a privacy patch in the size of the user can conceal only the moving people from the outside and leave the rest of the house fully open (Telhan et al. 2010).

\section{Conclusions}

To sum up, this research informs the design from a pragmatically standpoint on different items, the use and distribution of internal spaces, the relation between inside and outside and in particular the use of windows as interfaces for social interactions. Furthermore, this research informs the theoretical approach on social sustainability, in some major directions: 
- To include the cultural and social factors in any design process

- To sustain strategies for social interaction and participation

- To works as a translator able to create and maintain relations and to foster communication

- To provide instruments for people to understand and address local problems

- To support participation in the creation of a collective domain

The local cultural environment people share, change radically the mode they organize the space of their houses; this mode communicate at the same time within the inhabitants and with the outside community. The house is simultaneously a protected and protective inner space to feel sheltered and an outer space working as an interface with the public sphere; those two dimensions are intertwined and complementary. The act of modifying the physical space allows the inhabitants to better understand themselves and to communicate and share their beliefs and what they considered significant in life.

The home space is processed and modified by communication signs narrating about the uniqueness and the identity, the needs and the wishes of the inhabitants. Furthermore, the house conveys values based both on the person singularity - i.e. comfort, protection, privacy or property - and on the person public dimension - i.e. belonging, patriotism, community participation, and politics. The house is more than a physical location, as a result of the interactions with its dwellers it becomes its self a cultural environment: 'The extent to which the physical environment is elaborated with communicative signs that reveal the specific characteristics of the inhabitants is, with language, one of the distinguishing feature of human life. Although we live in physical environments, we create cultural environments within them. We continually personalize and humanize the given environment as a way of both adapting to it and creating order and significance' (Csikszentmihalyi and Halton 1981).

In this framework it becomes obvious how social sustainable design discourse should include the cultural and social factors. The approach to social sustainability in design practice been described in this paper, seeks to push forward the sustainable architecture and building techniques in order to promote and experiment new way of sustaining social behaviors. As McKenzie has stated 'the criteria for inclusion as a 'social sustainability project' are that the project must be innovative, effective, sustainable (in the sense that the resources it requires are renewable), and have potential for replication (in the sense that it can serve as a model for generating projects elsewhere)'. This research adds a further dimension to the existing criteria: not only a project must empower individuals and communities promoting the system enabling capability (Manzini 2006) but also should take into account the socio-cultural dimension of its design, sustaining new strategies for social interaction, participation and communication.

Fostering communication among people and improving the ability of the house space to work as a symbolic environment addressing both the inside users and the outside context is the key concept for accomplish a more social sustainable design. In other words social relation are matters of communication among subject and in becoming a platform for learning, sharing and connecting the house can partake in the 
moving to a more sustainable society. Social sustainable design works as a translator able to create and maintain relations among people and information. Translation means the ability of link technological innovation and local culture to assist and support the individual understanding of our changing reality. When design addresses social sustainability it encourages integration against separation both between people and communities. Social sustainable design allows participation reducing loneliness and separation as a result of its ability in fostering communication to create and maintain links between people who belong to the same community and connect diverse communities. Technologies designed within social sustainability are those who foster the relation between social imaginary and real practice.

Furthermore, social sustainability in design means to support participation in the creation of a collective domain; this space is the complex web of habits, values, preferences, and culture of each individual intertwined and co-created with other individuals.

Roger Bastide (1970) said: 'It is not the group as such that explains to us the communal memory; more precisely it is the structure of the group that gives us the picture of communal memory, that is no longer defined as communal conscience, but rather as a system of interrelations of individual memories. If the other person is necessary in order to remember, it is not because 'I' and 'the other' are immersed in the same social thought, but because our personal memories are united with memories of other people within a balanced game made up of mutual and complementary images.'

In conclusion is the commitment and participation in this collective domain that consent a community to give birth to creative and innovative solutions to local and global problems.

Acknowledgment. We would like to acknowledge the contributions of the Mobile Experience team to the development of our paper, research and design. This research was conducted within the Green Home Alliance between the Mobile Experience Lab at the Massachusetts Institute of Technology and the Fondazione Bruno Kessler, in Trento, Italy.

\section{References}

1. Baines, J., Morgan, B.: Sustainability Appraisal: A Social Perspective. International Institute for Environment and Development, London (2004)

2. Barron, L., Gauntlett, E.: Model of social sustainability. Housing and Sustainable Communities Indicators Project. Western Australian Council of Social Service, Perth (2002)

3. Bastide, R.: Mémoire collective et sociologie du bricolage. L'Année Sociologique 21(3), 65-108 (1970)

4. Bramley, G., Dempsey, N., Power, S., Brown, C.: What is 'social sustainability'and how do our existing urban forms perform in nurturing it. In: Planning Research Conference, Bartlett School of Planning. University College, London (2006)

5. Colantonio, A.: Social sustainability: a review and critique of traditional versus emerging themes and assessment methods. Loughborough University, Loughborough (2009) 
6. Colantonio, A., Lane, G.: Measuring Social Sustainability: Best Practice from Urban Renewal in the EU. EIBURS Working Paper Series (January 2007)

7. Csikszentmihalyi, M., Halton, E.: The Meaning of Things: Domestic Symbols and the Self. Cambridge University Press, Cambridge (October 30, 1981)

8. Elkington, J.: Cannibals with Forks: The Triple Bottom Line of 21st Century Business. New Society Publishers (September 1, 1998)

9. Future, C.: The Brundtland Report. United Nations World Commission (1987)

10. G.V.R.D., The Social Components of Community Sustainability: A Framework. TAC Social Issues Subcommittee, Vanvouver (2004)

11. Gasparatos, A., El-Haram, M., Horner, M.: The argument against a reductionist approach for assessing sustainability. In: International Conference on Whole Life Urban Sustainability and its Assessment, SUE-MoT Conference Proceedings Glasgow, UK, pp. 27-29 (2007)

12. Keenan, T.: Windows: of vulnerability. The Phantom Public Sphere 5. Unversity Minnesota Press (1993)

13. Lilley, D.: Design for sustainable behaviour: strategies and perceptions. Design Studies (2009)

14. Littig, B., Griessler, E.: Social sustainability: a catchword between political pragmatism and social theory. International Journal of Sustainable Development 8(1), 65-79 (2005)

15. Lyndon, D., Moore, C.W.: Chambers for a Memory Palace. The MIT Press, Cambridge Mass (1996)

16. Manzini, E.: Design for sustainability. How to design sustainable solutions. Sustainable Design (2006)

17. New design knowledge. Design Studies 30(1), 4-12 (2009)

18. McKenzie, S.: Social sustainability: towards some definitions. In: Magill. Hawke Research Institute Working Paper Series (2004), https://www.sapo.org.au/binary/binary141/Social.pdf

19. von Meiss, P.: Elements of Architecture. Van Nostrand Reinhold International, London (1990)

20. Mitchell, W.J., Casalegno, F.: The Connected Sustainable Home (2008), http: //moble.mit.edu/fbk

21. Sinner, J., Baines, J., Crengle, H., Salmon, G., Fenemor, A., Tipa, G.: Sustainable Development: A summary of key concepts. Ecologic Research Report 2 (2004)

22. Telhan, O., Casalegno, F., Park, J., Kotsopoulos, S., Yu, C.: Interaction Design with Building Facade, Cambridge, MA (January 25, 2010) 